\title{
Synthesis of Cyclohexanones through a Catalytic Cationic Cycliza- tion of Alkynols or Enynes
}

\author{
Pedro Alonso, Raquel Fontaneda, Pilar Pardo, Francisco J. Fañanás* and Félix Rodríguez* \\ Instituto Universitario de Química Organometálica “Enrique Moles”, Universidad de Oviedo, Julián Clavería 8, E-33006 \\ Oviedo, Spain
}

Supporting Information Placeholder

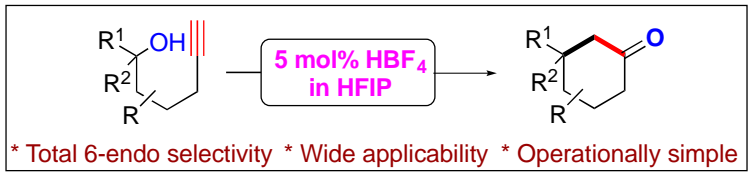

\begin{abstract}
A novel procedure for the synthesis of cyclohexanones from alkynol or enyne derivatives through a cationic cyclization has been developed. Key points to get the six-membered ring derivatives are the use of starting materials containing a terminal alkyne, the use of tetrafluoroboric acid as promoter of the cationic cyclization and the appropriate election of 1,1,1,3,3,3hexafluoropropan-2-ol (HFIP) as solvent. This strategy can be extended to the biomimetic cationic cyclization of several terpenederived polyenynes.
\end{abstract}

Cyclization reactions through cationic intermediates have been widely used over the years as a valuable tool to construct carbo- and heterocyclic compounds. ${ }^{1}$ A schematic overall sequence of this type of reactions is shown in Scheme 1a, and they involve starting materials I containing an initiating (A) and a terminating (B) functional group. Primarily, the initiating unit is activated to generate a cationic intermediate II that is intramolecularly trapped by the terminating group in a cyclization step. The new formed cation III is somehow stabilized to give the final neutral cyclic compound IV. Much of progress in this area stems from the development of appropriate initiating functionalities (A) while terminating groups (B) are frequently limited to usual heteroatom-centered nucleophiles, alkenes or arenes. Though, the use of alkynes as the terminating functionality has been scarcely studied. ${ }^{2}$ In this context, we have recently reported the reaction of alkynol derivatives 1 to give interesting cyclic alkenyl triflates and halides $\mathbf{4}$ through a process that involves the initial formation of cation $\mathbf{2}$ and subsequent endo-cyclization to form cyclic alkenyl cation $\mathbf{3}$ that it is finally trapped by the corresponding anion (Scheme 1b). ${ }^{3}$ Following with our interest in this field, we thought on the possibility of extending this method to the synthesis of cyclic ketones 6 that are valuable synthetic scaffolds (Scheme 1b). Thus, we proposed that the molecule of water formed in the initial dehydration reaction could trap the cyclic alkenyl cation $\mathbf{3}$ to give the enol $\mathbf{5}$, which is converted into the cyclic ketone $\mathbf{6}$ through a keto-enol tautomerization. At this point, a work reported by T. Jin, Y. Yamamoto and co-workers on the synthesis of cycloalkyl ketone derivatives $\mathbf{8}$ through a triflic acid catalyzed cationic cyclization of alkynols 7 should be mentioned. ${ }^{4}$ It is important to remark that this work is limited to alkynol derivatives 7 containing internal alkynes $(\mathrm{R} \neq \mathrm{H})$. The use of this type of alkynes has a crucial impact on the cyclization mode (endo or exo).
Scheme 1. Cationic cyclizations. Previous work and our proposal.

a) Cationic cyclizations. Concept

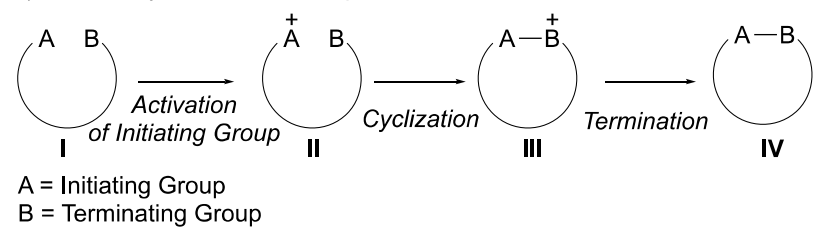

b) Our recent work (ref. 3) and proposal

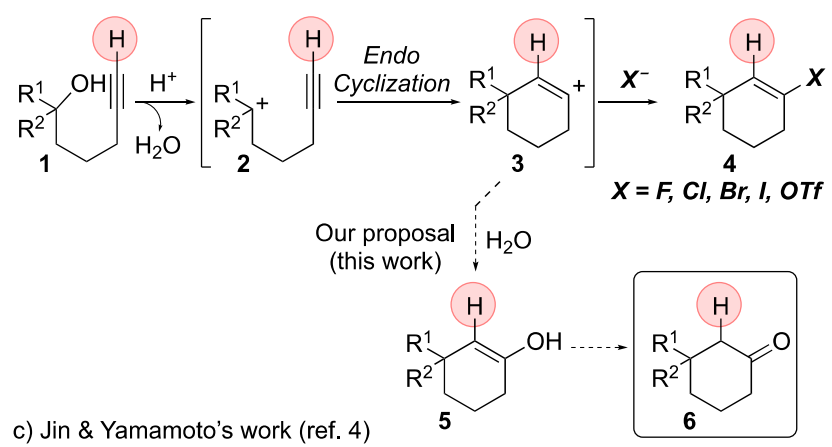

Jin \& Yamamoto's work (ref. 4)

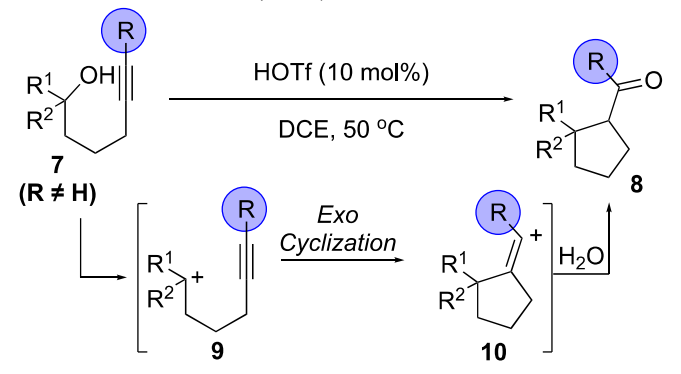


Thus, after the initial formation of cation 9, the cyclization process occurs through a exo-mechanism to give an exocyclic alkenyl cation $\mathbf{1 0}$ and finally the cycloalkyl ketone derivatives 8. Surprisingly, terminal alkynes were not considered in this work. In this context, we knew from our own previous work that, contrary to what occurs with internal alkynes, the use of terminal alkynes (such as 1) favored the cyclization through an endo-mechanism and thus, under appropriate conditions cycloalkanones $\mathbf{6}$ could be obtained instead of cycloalkyl ketones $\mathbf{8}^{3,5}$ Herein, we present the successful development of the proposed cationic cyclization reaction for the synthesis of cyclohexanone derivatives.

In our initial experiments, alkynol 1a, comprising a terminal alkyne, was used as a model substrate to explore the viability of the proposed strategy (Table 1). As a starting point, we took the experimental conditions reported by Jin, Yamamoto and co-workers in their synthesis of cycloalkyl ketones $\mathbf{8}$ from alkynols 7 containing internal alkynes. ${ }^{4}$ Thus, alkynol 1a was treated with $10 \mathrm{~mol} \%$ of triflic acid (TfOH) in 1,2dichloroethane (DCE) as solvent at room temperature for 16 hours (Table 1, entry 1). Under these conditions, instead of the expected ketone $\mathbf{6 a}$ we observed the exclusive formation of the enyne derivative 11a along with a small amount (< $10 \%$ ) of the cyclic alkenyl chloride 4a. Interestingly, when 1 equivalent of triflic acid was used we could isolate the cyclic alkenyl chloride $\mathbf{4 a}$ in $72 \%$ yield but formation of the desired ketone 6a was not observed (Table 1, entry 2). These initial experiments showed a differential reactivity of alkynol derivatives such as 1a comprising a terminal alkyne when compared with alkynols 7 containing internal alkynes. Thus, it seems that, under similar conditions, the endocyclic alkenyl cation 3 preferentially reacts with a chloride coming from the solvent (DCE) while the exocyclic cation $\mathbf{1 0}$ tends to react with the water formed in the initial step of the reaction. Formation of alkenyl chlorides similar to $4 \mathbf{a}$ instead of ketone derivatives could be the reason why terminal alkynes were not considered in that previous work. Thus, after verifying that the conditions reported by Jin, Yamamoto and coworkers were not appropriate to get our desired cyclic ketone $\mathbf{6 a}$, we started to check different reaction conditions. At this point, it seemed clear that the obvious option to avoid the formation of the undesired alkenyl chloride $\mathbf{4 a}$ was the replacement of 1,2-dichloroethane (source of the chlorine atom of 4a) with some other chlorine-free solvent. However, when the reaction was performed in hexane we observed the exclusive formation of the alkenyl triflate $\mathbf{4 b}(98 \%$; Table 1 , entry 3 ). This product is formed when the alkenyl cation $\mathbf{3}$ is trapped by the counterion (triflate) of the acid promoter (TfOH). ${ }^{3 \mathrm{~b}}$ Again, it seems that trapping of cation 3 by the water formed in the first step of the process is not favored under these conditions. Formation of the undesired alkenyl triflate 4b was also observed when other typical solvents were used. Thus, to avoid the formation of triflate $\mathbf{4 b}$ we decided to change the acid promoter from triflic acid to tetrafluoroboric acid $\left(\mathrm{HBF}_{4} \cdot \mathrm{OEt}_{2}\right)$. First, we tried the reaction with this acid by using 1,2-dichloroethane (DCE) as solvent (Table 1, entry 4). Unfortunately, the desired ketone 6a was not formed and the only product we could isolate in high yield (92\%) was the chloride 4a. Next, we tried the reaction with a chlorine-free solvent such as hexane (Table 1 , entry 5). Under these conditions, a new product, the alkenyl fluoride $\mathbf{4 c}$, was formed in high yield (92\%). This compound is formed when the alkenyl cation $\mathbf{3}$ is trapped by a fluoride coming from the tetrafluroborate anion. All these experiments demonstrate that the synthesis of the desired cyclic ketones $\mathbf{6}$ was not as easy as initially thought because trapping of alkenyl cation $\mathbf{3}$ by different nucleophilic partners present in the reaction media seemed to be favored over the desired trapping with water. However, after further experimentation we found that the use of tetrafluoroboric acid as promoter in combination with 1,1,1,3,3,3hexafluoropropan-2-ol (HFIP) as solvent was the key point to success to achieve the synthesis of ketones $6 .{ }^{6}$ In fact, when alkynol 1a was treated with 1 equivalent of tetrafluoroboric acid in HFIP as solvent we were able to isolate the ketone $\mathbf{6 a}$ in $85 \%$ yield (Table 1, entry 6). Interestingly, the amount of the acid could be reduced to just 0.05 equivalents without erosion in the chemical yield (90\%; Table 1, entry 7). It is important to remark that the cyclization occurred exclusively through a 6-endo mode and formation of alternative products coming from a 5-exo mode was not observed.

Table 1. Initial experiments

\begin{tabular}{|c|c|c|c|c|}
\hline $\begin{array}{l}\mathrm{Ph} \\
\mathrm{Ph}^{-}\end{array}$ & $\mid \underset{25^{\circ} \mathrm{C}, 30 \mathrm{~min}}{\underset{\text { Solvent }}{\text { Acid }}} \mathrm{Ph}^{\mathrm{Ph}}$ & & 11a & $\begin{array}{l}\text { 4a }(X=C l) \\
4 b(X=O T f) \\
4 c(X=F)\end{array}$ \\
\hline $\begin{array}{l}\text { en- } \\
\text { try }\end{array}$ & acid (equiv) & solvent & $\begin{array}{c}\text { prod- } \\
\text { uct }\end{array}$ & yield $(\%)$ \\
\hline 1 & $\mathrm{TfOH}(0.1)$ & DCE & $11 \mathbf{a}^{a, b}$ & 87 \\
\hline 2 & TfOH (1) & DCE & $4 \mathbf{a}^{c}$ & 72 \\
\hline 3 & TfOH (1) & Hexane & $4 b$ & 98 \\
\hline 4 & $\mathrm{HBF}_{4} \cdot \mathrm{OEt}_{2}(1)$ & DCE & $\mathbf{4} \mathbf{a}^{b}$ & 92 \\
\hline 5 & $\mathrm{HBF}_{4} \cdot \mathrm{OEt}_{2}(1)$ & Hexane & $\mathbf{4} \mathbf{c}^{d}$ & 92 \\
\hline 6 & $\mathrm{HBF}_{4} \cdot \mathrm{OEt}_{2}(1)$ & HFIP & $6 \mathbf{a}$ & 85 \\
\hline 7 & $\mathrm{HBF}_{4} \cdot \mathrm{OEt}_{2}(0.05)$ & HFIP & $6 a$ & 90 \\
\hline
\end{tabular}

${ }^{a}$ Formation of $\mathbf{4 a}(<10 \%)$ was also detected. ${ }^{b}$ Reaction extended for 16 hours. ${ }^{c}$ Formation of $\mathbf{4 b}(10 \%)$ was also detected. ${ }^{d}$ Reaction extended for 8 hours.

Encouraged by the initial result above mentioned, we explored the scope of the reaction. For this purpose, a representative set of alkynols 1 were subjected to the optimized reaction conditions (Scheme 2). To our delight, we observed that most of the cyclohexanones $\mathbf{6}$ were isolated in high yields. As shown, not only tertiary but also secondary benzylic alcohols 1 could be used (see products $\mathbf{6 d , f , k , r ) . ~ I n ~ t h i s ~}$ context, it should be noted that secondary alcohols were not considered in the previous work from Tien and Yamamoto on the synthesis of cycloalkyl ketones with internal alkynes. ${ }^{4}$ However, in our case the use of this type of alcohols does not seem a problem. Interestingly, this methodology could be applied to the synthesis of naphthalenone derivatives $(\mathbf{6 g}, \mathbf{k})$. Substitution at different positions of the alkyl chain connecting the alcohol and alkyne functionalities in $\mathbf{1}$ is also allowed (see products $\mathbf{6 g}, \mathbf{k}, \mathbf{m}, \mathbf{n}, \mathbf{o , r}$ ). Particularly remarkable are those products containing functional groups that allow further functionalization. For example, ester-derived compounds 6o,r could be easily transformed through this functionality. We were also able to get the alkyne-substituted cyclohexanone derivative $\mathbf{6 q}$ from diyne 1q. It should be 
noted that in this case we observed exclusive reaction through one of the alkyne moieties. In other words, we observed the exclusive formation of a six-membered cyclic ketone in a process where the second alkyne of $\mathbf{1 q}$ remained untouched. Interestingly, the pendant alkyne of $\mathbf{6 q}$ could be used for additional functionalization. The spirocyclic functionalized ketone derivative $\mathbf{6 m}$ was also available in high yield. Furthermore, the new cyclization reaction herein presented does not seem to be limited to the synthesis of carbocyclic ketones. Thus, the piperidin-3-one derivative $\mathbf{6 p}$ could also be accessed using in this case triflic acid (TfOH) as promoter. The last example shown in Scheme 2 (compound 6r) is particularly interesting. This product was obtained as a single diastereoisomer in very high yield starting from a 1:1 mixture of diastereisomers of alkynol 1r. This result is significant because it indicates that it is possible to synthesize enantiomerically pure products 6 through a substratecontrolled process. Moreover, it also shows that the stereocenter at 2-position of the starting alcohol directs the formation of the new stereocenter to get a trans-isomer independently of the stereochemistry of the stereocenter at 1position of the alcohol 1 .

Scheme 2. Synthesis of cyclic ketone derivatives 6.
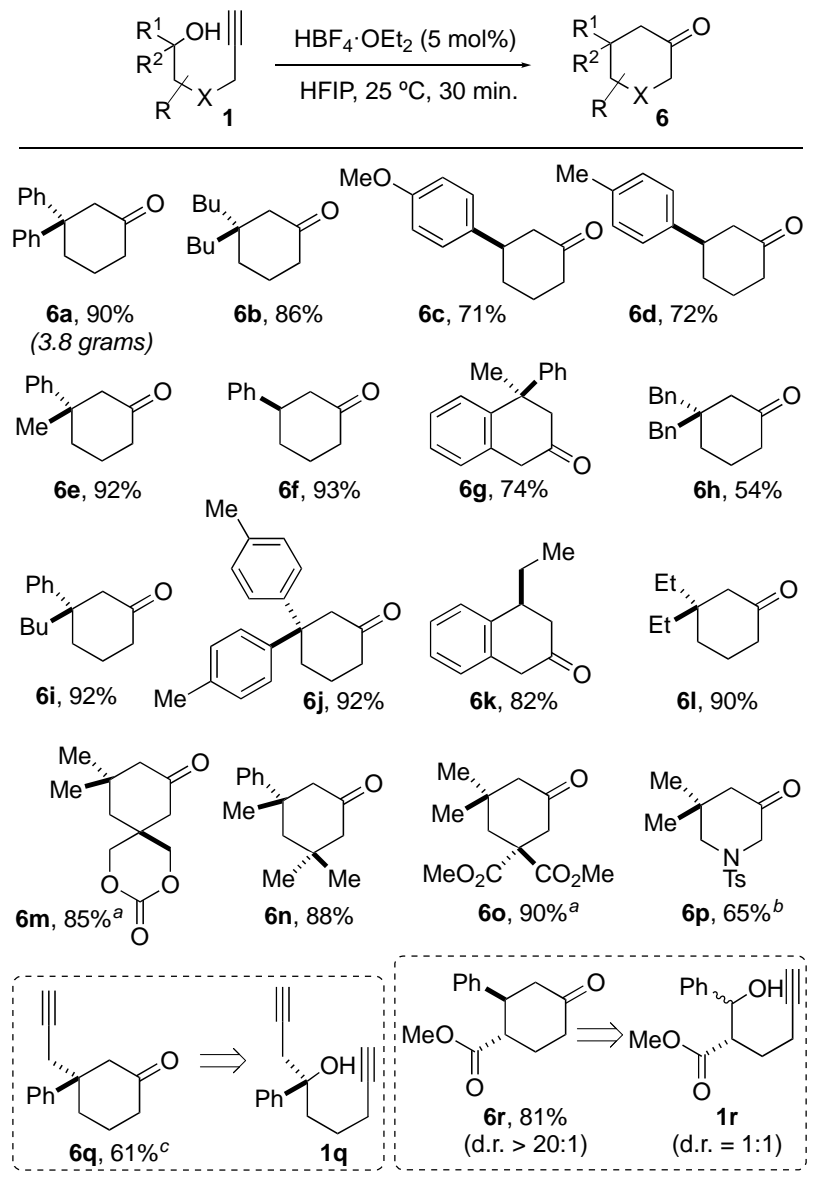

${ }^{a}$ Reaction performed with 1 equivalent of $\mathrm{HBF}_{4} \cdot \mathrm{OEt}_{2}$ at 60 ${ }^{\circ} \mathrm{C} .{ }^{b}$ Reaction performed with triflic acid (TfOH, 1 equivalent) instead of $\mathrm{HBF}_{4} \cdot \mathrm{OEt}_{2}$ in the presence of additional water (2 equiv). ${ }^{c}$ Additional water (10 equiv) was required.
Furthermore, we verified that this new reaction of synthesis of cyclohexanone derivatives could be performed on a gram scale by the smooth preparation of $3.8 \mathrm{~g}$ of $\mathbf{6 a}$ in one batch. Finally, this reaction seems to be limited to the synthesis of six-membered ring cyclic derivatives as we were not able to extend the method to the synthesis of other cycloalkanone derivatives from analogues of $\mathbf{1}$ with a shorter or longer alkyl chain.

Having demonstrated the practicability of our methodology on simple substrates, we next studied the behavior of more challenging polyenyne derivatives 12 under the optimized conditions (Scheme 3). For this purpose, several commercially available terpenes (geraniol, nerol and farnesol) were easily manipulated to install a terminal triple bond following simple procedures described in the literature. ${ }^{7}$

Scheme 3. Synthesis of ketone derivatives 13 by a biomimetic cyclization process of polyenynes $\mathbf{1 2}$.

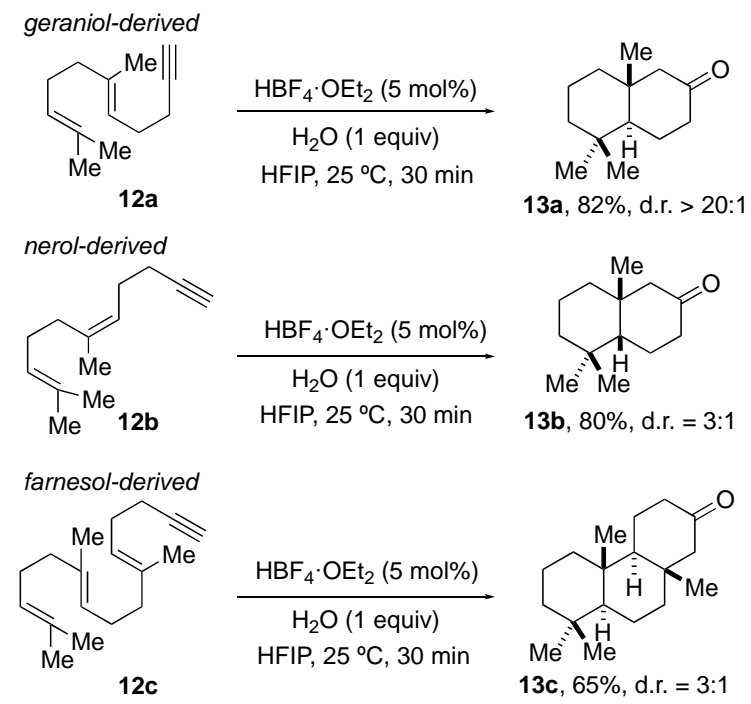

Then, the resulting polyenynes $\mathbf{1 2}$ were tested under conditions similar to those above described. Notwithstanding, as these substrates lack a hydroxyl group and formation of the initial cation is due to an alkene protonation rather than a dehydration reaction, one equivalent of water had to be added to the reaction mixture in order to effectively trap the final alkenyl cation. By effecting this simplistic modification of our procedure, a small set of rather complex polycyclic ketones 13 could be accessed (Scheme 3 ). ${ }^{8}$ Remarkably, transdecalone 13a could be isolated in excellent $82 \%$ yield and namely as a single diastereoisomer (d.r. > 20:1). On the other hand, bicyclic and tryciclic ketones $\mathbf{1 3 b}$ and $\mathbf{1 3 c}$ were isolated with equally good yields though as a mixture of diastereoisomers (d.r. $=3: 1){ }^{9}$

In conclusion, a new tetrafluoroboric acid-catalyzed carbocyclization of alkynols and enynes to synthesize cyclohexanones has been developed. The procedure described in this manuscript complements and challenges existing methodologies in the cationic carbocyclization arena. More precisely, employment of alkynols and enynes decorated with terminal alkynes leads to the clean formation of cyclohexanones through exclusive 6-endo mode of cyclization. Moreover, we have demonstrated the feasibility of biomimetic polyene cyclizations as a new an interesting way to access polycyclic 
ketones in a highly efficient manner. The simplicity of the starting materials and procedures coupled with the wide importance of cyclohexanone derivatives makes the reaction here described an appropriate tool to consider in organic synthesis programs.

\section{ASSOCIATED CONTENT}

\section{Supporting Information}

The Supporting Information is available free of charge on the ACS Publications website.

Experimental details and characterization data for all new compounds (PDF)

\section{AUTHOR INFORMATION}

\section{Corresponding Author}

*e-mail: fjfv@uniovi.es.

* e-mail: frodriguez@uniovi.es.

\section{Notes}

The authors declare no competing financial interest.

\section{ACKNOWLEDGMENTS}

We gratefully acknowledge financial support from MINECOSpain (Grants No CTQ2013-41336-P and CTQ2016-76794-P) and MEC-Spain (FPU-predoctoral grant to P. A. and FPIpredoctoral grant to P. P.).

\section{REFERENCES}

(1) Thebtaranonth, C.; Thebtaranonth, Y. In Cyclization Reactions; CRC Press: Boca Ratón, 1994; ch 2, p 5.

(2) For some cationic cyclizations with different initiating groups but implying an alkyne as terminating group, see: (a) Peterson, P. E.; Kamat, R. J. J. Am. Chem. Soc. 1969, 91, 4521-4527. (b) Lansbury, P. T.; Demmin, T. R.; DuBois, G. E.; Haddon, V. R. J. Am. Chem. Soc. 1975, 97, 394-403. (c) Johnson, W. S.; Escher, S.; Metcalf, B. W. J. Am. Chem. Soc. 1976, 98, 1039- 1041. (d) van Tamelen, E. E.; Leiden, T. M. J. Am. Chem. Soc. 1982, 104, 20612062. (e) Johnson, W. S.; Berner, D.; Dumas, D. J.; Welch, P. J. R. J. Am. Chem. Soc. 1982, 104, 3508-3510. (f) van Tamelen, E. E.; Faler, D. L. Proc. Natl. Acad. Sci. USA 1985, 82, 1879-1880. (g) Johnson, W. S.; Fletcher, V. R.M.; Chenera, B.; Bartlett, W. R.; Tham, T. S.; Kullnig, R. K. J. Am. Chem. Soc. 1993, 115, 497-504. (h) Fish, P. V.; Johnson, W. S. J. Org. Chem. 1994, 59, 2324-2335. (i) Balog, A.; Geib, S. J.; Curran, D. P. J. Org. Chem. 1995, 60, 345-352. (j) Sun, J.; Kozmin, S. A. J. Am. Chem. Soc. 2005, 127, 13512-13513. (k) Jin, T.; Himuro, M.; Yamamoto, Y. J. Am. Chem. Soc. 2010, 132, 5590-5591.

(3) (a) Alonso, P.; Pardo, P.; Fañanás, F. J.; Rodríguez, F. Chem. Commun. 2014, 50, 14364-14366. (b) Alonso, P.; Pardo, P.; Galván, A.; Fañanás, F. J.; Rodríguez, F. Angew. Chem. Int. Ed. 2015, 54, 15506-15510. (c) Alonso, P.; Pardo, P.; Fontaneda, R.; Fañanás, F. J.; Rodríguez, F. Chem. Eur. J. 2017, 23, 13158-13163.

(4) Jin, T.; Himuro, M.; Yamamoto, Y. Angew. Chem. Int. Ed. 2009, 48, 5893-5896.

(5) For examples of 6-endo cationic cyclizations with substrates containing a terminal alkyne see: (a) Miranda, P. O.; Díaz, D. D.; Padrón, J. I.; Bermejo, J.; Martín, V. S. Org. Lett. 2003, 5, 19791982. (b) Miranda, P. O.; Ramírez, M. A.; Martín, V. S.; Padrón, J. I. Org. Lett. 2006, 8, 1633-1636. (c) Miranda, P. O.; Carballo, R. M.; Martín, V. S.; Padrón, J. I. Org. Lett. 2009, 11, 357-360. (d) Beaulieu, M.-A.; Guérard, K. C.; Maertens, G.; Sabot, C.; Canesi, S. J. Org. Chem. 2011, 76, 9460-9471; e) Desjardins, S.; Andrez, J.-C.; Canesi, S. Org. Lett. 2011, 13, 3406-3409. (f) Saikia, A. K.; Ghosh, P.; Kautarya, A. K. RSC Adv. 2016, 6, 44774-44781. On the other hand, for examples of 5-exo cationic cyclizations of substituted alkynes, see: (g) Johnson, W. S.; Brinkmeyer, R. S.; Kapoor, V. M.; Yarnell, T. M. J. Am. Chem. Soc. 1977, 99, 8341-8343. (h) Nikolic, N. A.; Gonda, E.; Longford, C. P. D.; Lane, N. T.; Thompson, D. W. J. Org. Chem. 1989, 54, 2748-2751. (i) Cantagrel, G.; Carné-Carnavalet, B.; Meyer, C.; Cossy, J. Org. Lett. 2009, 19, $4262-4265$

(6) For an excellent account on the versatility of 1,1,1,3,3,3hexafluoropropan-2-ol (HFIP) as solvent, see: I. Colomer, A. E. R. Chamberlain, M. B. Haughey, T. J. Donohoe, Nature Rev. 2017, 1, 0088 (DOI: 10.1038/s41570-017-0088).

(7) (a) Paz, J. L.; Rodrigues, J. A. R. J. J. Braz. Chem. Soc. 2003, 14, 975-981. (b) Domingo, V.; Lorenzo, L.; Quilez del Moral, J. F.; Barrero, A. F. Org. Biomol. Chem. 2013, 11, 559-562.

(8) Ohloff, G.; Näf, F.; Decorzant, R.; Thommen, W.; Sundt, E. Helv. Cmim. Acta 1973, 56, 1414-1448.

(9) Based on NMR studies performed on the 3:1 mixture of diastereoisomers of $\mathbf{1 3 c}$, we tentatively assigned the structure of the minor isomer as the other trans,trans-perhydrophenanthrenone derivative. 